Lee, K. (accepted). Implementing computer-mediated intercultural communication in English education: A critical reflection on its pedagogical challenges. Journal of Computer Assisted Learning.

\title{
Implementing computer-mediated intercultural communication in English education: A critical reflection on its pedagogical challenges
}

Kyungmee Lee

Lecturer

Lancaster University, The Department of Educational Research, County South, Lancaster, Lancashire LAI 4YD, United Kingdom

k.lee23@lancaster.ac.uk 
Lee, K. (accepted). Implementing computer-mediated intercultural communication in English education: A critical reflection on its pedagogical challenges. Journal of Computer Assisted Learning.

\section{Implementing computer-mediated intercultural communication in English education:}

\section{A critical reflection on its pedagogical challenges}

Integrating Computer-Mediated Intercultural Communication (CMIC) activities into language curricula has been discussed as an innovative approach to supporting students in developing intercultural communicative competence, an essential skill in today's internationalised society. Despite the increasing number of successful examples reporting positive outcomes of adopting CMIC activities in language learning environments, it has also been noted that there are a number of significant pedagogical challenges observed when the CMIC activities are introduced into classrooms. However, previous studies tend only to briefly mention some of those challenges and to list general solutions to them, rather than deeply engaging with the issues and their educational and social consequences upon students learning and language practices. Thus, this qualitative case study aims to investigate specifically such issues: it documents diverse pedagogical challenges faced by Korean students and a teacher in their EFL classroom, in which a series of CMIC activities were set up and conducted. The challenges analysed in this paper include: the unrealistically high implementation cost (which is not merely financial); diverse educational inequality issues created by irreducible gaps in students' socio-economic backgrounds and perpetuated within CMIC activities; and the unresolved struggles to develop positive student subjectivities and linguistic identities. In conclusion, the article proposes three teaching and instructional principles, drawn in turn from the two closely interrelated theories: Multiliteracies Pedagogy and Critical Pedagogy. Fundamentally, the author argues that effective adoption of the CMIC activities needs a more pedagogically, socially, and culturally sensitive approach.

Key words: computer-mediated intercultural communication; international telecollaboration; computer-assisted language learning; multiliteracies pedagogy; critical pedagogy

\section{Introduction}

In the era of globalisation, the importance of English as a "world language" (Brutt-Griffler, 2002) has been growing across the world. English communicative competence is considered one of the necessary skills for today's young students to successfully participate in a highly internationalised society (Kennedy, 2006; Kramsch, 2014). It has also been emphasised as one of the essential roles of contemporary schools to help their students to become intercultural speakers who will be successful not only in speaking the English language but also in developing a relationship with people of other languages and cultures. For example, Byram's (1997; 2012) model of Intercultural Communicative Competence introduces the "intercultural dimension" into language teaching practice and focuses on supporting learners in developing their own identities as well as those of the 'others' in the increasingly 
Lee, K. (accepted). Implementing computer-mediated intercultural communication in English education: A critical reflection on its pedagogical challenges. Journal of Computer Assisted Learning.

multicultural society. Researchers who have examined English education systems in non-English speaking countries, however, have observed a significant discrepancy between a growing societal emphasis on English-as-a-foreign language (EFL) learning and the perceived ineffectiveness of English curricula - particularly in public schools that extensively focus on grammar and translation exercises without providing authentic English communication opportunities (Butler, 2011; Coskun, 2011; Hu, 2005; Jeon, 2009; Nunan, 2003; Wong, 2012). The literature has highlighted multiple negative consequences of that discrepancy, which include: an excessive financial investment in private English education; unequal access to quality English instruction or communication opportunities; and an unproblematised dominance of Western (American) language, cultural values, norms, and world views within pedagogical practices and curriculum designs.

In parallel with the growing importance of intercultural communicative competence in English education, there is an increasing emphasis on the educational application of Computer-Mediated Communication (CMC) across various educational sectors. This has been driven by the rapid development of CMC technologies (e.g., online forums, blogs, social network sites, instant messenger, web-conferencing tools, email, etc.) and their prevalence in current students' learning and communication practice (see Alothman, Robertson, \& Michaelson, 2017; Asterhan, \& Bouton, 2017; Loncar, Barrett, \& Liu, 2014; Tang, \& Hew, 2017). For example, Genlott and Grönlund (2016) used communication technologies and enabled continuous classroom interaction and real-time formative teacher assessment in primary literacy and mathematics education contexts. Cheng and Jiang (2015) developed and introduced an online platform based on instant messenger to an art and design education context. Aghaee and Keller (2016) examined the use of online peer interaction and collaboration in Bachelor's and Master's thesis processes. Cho (2016) designed a discussion-based online course to facilitated participants' situated learning for pre-service teachers; and, Lee and Brett $(2013 ; 2015)$ took a similar pedagogical approach to inservice teacher education. Similar attempts have been also made in international classroom contexts, in order to enable and facilitate intercultural communication among students of different languages and cultures (see Ambrose et al, 2017 in global health education; Briones, \& Lara, 2016 in ethics education).

In this context, integrating Computer-Mediated Intercultural Communication (CMIC, or often, 'international telecollaboration') activities into EFL language curricula has been discussed as a particularly promising alternative to the currently dominant practices of English teaching and learning (more broadly, literacy education). An increasing number of studies have reported positive outcomes of adopting CMIC activities in language learning environments. For example, Yang and Chen (2014) associated Taiwanese students' increased level of learning motivation and English communicative competence with a series of CMIC activities involving other students in Dubai, Pakistan and the USA. 
Lee, K. (accepted). Implementing computer-mediated intercultural communication in English education: A critical reflection on its pedagogical challenges. Journal of Computer Assisted Learning.

Wach (2015) investigated the CMIC experiences of English learners from Poland and Romania and concluded that English learners' participation in an international telecollaboration project is effective both in developing their English communication skills and in increasing their intercultural awareness (in particular, an openness to cultural differences and a willingness to communicate with others with different beliefs). Based on her findings, Wach stressed the great potential of embracing various forms of CMC in foreign language teaching. Villar-Onrubia and Rajpal (2016) also reported positive outcomes of an educational initiative involving intercultural interactions between UK students and non-UK students who, it was suggested, improved both intercultural communicative competence and digital skills through their participation in the initiative. Liaw and English (2017) incorporated an international telecollaboration project in their communication classrooms and claimed that the participants, through selecting, reading, describing, and discussing their chosen objects of personal significance, increased their awareness of one another's identities and perceived their interlocutors as authentic individuals of different culture and language.

Most of the current literature concerning CMIC activities in language curricula focuses on positive aspects of students' learning experiences and on the pedagogical potential of new CMC technologies reporting both in many cases (see more examples in Bray, 2010; Jin, 2015; Machado, et al., 2016; O'Dowd, 2007; Schenker, 2012; Tanghe \& Park, 2016). However, it has also been noted that "online intercultural exchanges are extremely complex and dynamic educational contexts" (Turula, 2017, p. 21), which are not without significant challenges. In fact, although positive narratives continues to dominate, a number of recent articles document significant pedagogical issues observed when a telecollaboration project is introduced into a conventional classroom. For example, Carr (2016) noticed that some students find it difficult to get access to certain CMC tools, and that conflicting calendars among different schools make it a challenge for some students to fully participate in multi-institutional projects. Kayumova and Sadykova (2016) observed that students struggled with communicating and working with their international partners with very different cultural beliefs and learning approaches, which caused a failure in their telecollaboration projects. Lázár (2015) also suggested that students generally perceive that developing a relationship with their partner is challenging, especially when different cultural conceptions cause significant mistakes in intercultural communication. Rudenko and Krylova (2016) concluded that students' repetitive speech 'mistakes' decreases their subsequent willingness to communicate with their foreign partners. In a similar vein, Ke (2016) reported that some students find it too difficult to develop a positive and stable linguistic identity. They tend to position themselves as a 'deficient' non-native speaker and experience a high level of anxiety in intercultural communication settings.

It is then perhaps unsurprising that many researchers have emphasised that well-designed activities 
Lee, K. (accepted). Implementing computer-mediated intercultural communication in English education: A critical reflection on its pedagogical challenges. Journal of Computer Assisted Learning.

with ongoing teacher and technical support are essential factors for the successful adoption of CMIC activities in learning environments. The factors highlighted include tightly structured tasks and task sequences (Kurek \& Müller-Hartmann, 2017), carefully planned activities with clearly set deadlines and a diverse range of available technologies (Kayumova \& Sadykova, 2016), more guided and demanding tasks and in-depth classroom discussion (Peiser, 2015), and an emphasis on teacher guidance and presence (Turula, 2017). However, with a few exceptions (see Ware \& Kessler, 2016), it is difficult to find a published work that concentrates upon those pedagogical challenges emerging from (or during) CMIC activities in classrooms - especially work providing a comprehensive description of students' experiences with those issues and teachers' effort to address them. Thus, this case study aims to investigate specifically such challenges by asking a question like "What pedagogical challenges and social issues are observed in a CMIC-implemented EFL classroom in South Korea?"

\section{A Theoretical Framework}

Tate (2007) argues that the task of a researcher, as an analyst, is to carry out reflexive translation of a particular social event under examination, and so that how the researcher interprets the event is entirely dependent upon which analytic lens he or she takes. Bryson and De Castell (1998) in their article ${ }^{1}$ effectively demonstrate how narratives about the same educational phenomenon (i.e., educational computing in school contexts) can be divergent, or often conflicting, among researchers with diverse analytic lenses. Therefore, this article, inspired by the authors' ideas above, aim to provide different, and hopefully more critical, narratives about CMIC activities in a language learning environment. To do so, the present author deploys two different, but potentially interrelated, theories of pedagogy: Multiliteracies Pedagogy and Critical Pedagogy.

\subsection{Multiliteracies Pedagogy}

Multiliteracies is first introduced by The New London Group (1996) as a way of conceptualizing a notion of literacy reflecting an increasing cultural and linguistic diversity in the current society with a multiplicity of text forms associated with various information and communication technologies.

Multiliteracies pedagogy is a teaching approach based on the epistemological assumption:

human knowledge is developed not as "general and abstract," but as embedded in social, cultural, and material contexts. Further, human knowledge is initially developed as part and

\footnotetext{
${ }^{1}$ This article, titled Telling tales out of school: Modernist, critical, and postmodern "true stories" about educational computing, includes three different interpretations of the same social event (which are rather contradictory to one another) using three different epistemological lenses.
} 
Lee, K. (accepted). Implementing computer-mediated intercultural communication in English education: A critical reflection on its pedagogical challenges. Journal of Computer Assisted Learning.

parcel of collaborative interactions with others of diverse skills, backgrounds, and perspectives joined together in a particular epistemic community, that is, a community of leaners engaged in common practices centered around a specific (historically and socially constituted) domain of knowledge. (The New London Group, 1996, p.82)

Multiliteracies pedagogy is accordingly explained by the group as "a complex integration of four factors" (p. 83): situated practice, overt instruction, critical framing, and transformed practice. Although the four interrelated factors may occur simultaneously in actual pedagogical settings, each factor respectively suggests the following principles:

- $\quad$ Situated Practice: Learners participate in meaningful multiliteracies practices within a community of leaners who can play various roles based on their backgrounds and experiences.

- Overt Instruction: The multiliteracies practices are guided and facilitated by teachers (or experts) who provide active interventions at "teachable" moments to help learners gain conscious awareness of what is being learned and how it is learned.

- Critical Framing: Learners are able to reflect on their learning process and denaturalise what they have learned and critically examine their multiliteracies practices in relation to their social and cultural contexts.

- $\quad$ Transformed Practice: Through this process, learners revise and change their meaning-making practices according to their own goals and values, which would ultimately have an effect on re-developing cultural practices or assumptions.

Thus, a central focus of multiliteracies pedagogy is to design learning environments that engage students in meaningful literacy practices involving multiple forms (or modes) of meaning-making experiences. The general principles suggested by multiliteracies pedagogy are correspondent to the predominant pedagogical ideas shared by social constructivist learning theorists who perceive learning as a knowledge construction process through participating in collaborative practices of social communities (e.g., Lave \& Wenger, 1991; Scardamalia \& Bereiter, 1993; Vygotsky, 1978). However, the essential goal of gaining conscious awareness of social problems (i.e., social inequality) and reforming cultural practices that cause those problems is a rather unique component of multiliteracies pedagogy.

English language education informed by multiliteracies pedagogy, therefore, needs to provide learners with opportunities to cognitively and critically engage with multimodal forms of meaningmaking practices within collective learning communities, but also in personally meaningful ways. Ultimately, the effective language learning practices would enable and encourage learners to invest in and 
Lee, K. (accepted). Implementing computer-mediated intercultural communication in English education: A critical reflection on its pedagogical challenges. Journal of Computer Assisted Learning.

negotiate their linguistic and cultural identities and develop critical language awareness, through which they can understand various power effects created by language use in their own cultural and social contexts (Cummins, 2001; 2004; Cummins, Brown, Sayers, 2007).

\subsection{Critical Pedagogy}

Critical pedagogy, grounded in the Frankfurt School's critical theory, aims to empower students to question and challenge dominant social beliefs and practices, which are often taken-for-granted by students themselves despite the negative effects that they have on their lives (Aronowitz \& Giroux, 1991; 1993; Freire, 1995; McLaren, 2003). This teaching approach foregrounds the unequal conditions of schooling, in relation to larger socio-economic inequality, and its oppressive social functions that serve to marginalize certain groups of students (Giroux, 1981). Bourdieu, in his book The forms of capital (1986), introduces three interlinked types of capital: economic capital, social capital, and cultural capital. Among them, cultural capital refers to the "inherited" properties of a person that are mostly gained from his or her family, providing him/her a higher status in a society. An unequal amount of cultural capital possessed by families from different social classes creates unequal conditions for their children's continuing acquisition of cultural capital (Bourdieu, 1991). Bourdieu's theory of cultural capital has been taken up by many critical pedagogues to unpack and decode the socialization (or marginalization) process of schooling (Apple, 1998; Lin, 1999; Sandoval, 2000; Willis, 2003).

Families from dominant social classes provide their children with initial advantages of cultural capital (in this case, the particular forms of knowledge required to succeed in the school system). For example, literacy (or academic skills more broadly) is a form of cultural capital. Children from different social classes tend to start their schooling with unequal levels of abilities to read and write, which then results in unequal educational experiences among them subsequently. Those children with more cultural capital do better in their schooling, benefit more from the school curriculum, and in turn obtain further cultural capita - more and faster - than those children from marginalized social classes. In this sense, the current educational system does not enable students to overcome different inequality issues in their lives, which are deeply rooted in the large socio-economic inequality. On the contrary, it supports and reproduces unequal power relationships between dominant and marginalized social classes (Aronowitz \& Giroux, 1991). Through this educational socialization process, therefore, the inequality among students from different social classes tends to be maintained and reinforced unless teacher and students consciously and collectively resist the reproduction mechanism and strive to disturb the socialization process. 
Lee, K. (accepted). Implementing computer-mediated intercultural communication in English education: A critical reflection on its pedagogical challenges. Journal of Computer Assisted Learning.

Discourse is another useful concept that can be discussed in relation to one particular form of cultural capital: namely, those learning attitudes that are considered right or appropriate in the current educational system. Discourse, understood as a set of knowledge, rules and regulations, is a central notion in Foucauldian analyses of power relations between disciplinary institutions (e.g., schools or prisons) and individuals who participate in institutional practices. According to Foucault (1990), discourse governs and controls people's thoughts and behaviours through different forms of institutional rules and regulations that exert disciplinary power upon people's thoughts and behaviours. Among multiple competing discourses in a social regime, certain dominant discourses decide which thoughts and behaviours are more legitimate than others (Foucault, 1995). Dominant discourses consist of a particular set of norms, which create different human subjectivities and divide people into often dichotomous groups: the "normal" and the "abnormal or problematic". In any school context, there will be some particular set of norms identifying good and bad learning attitudes and behaviours. Those norms (i.e., dominant discourses) in turn identify and classify students - for example as "a good versus bad student" or "an active versus passive student" (see Comber, 1997).

As a consequence, discourse imposes unequal values on different learning attitudes and skills and those that are more valued often turn into forms of cultural capital that privileged students are more likely to possess, and that disadvantaged students find it much more difficult to obtain. Yet, despite the controlling and discriminating nature of the disciplinary (i.e., educational) practices in school context, due to the taken-for-grantedness of discourse, it is almost impossible for individual students to challenge or resist the dominant discourse (Dean, 2010). Therefore, critical pedagogues call for the collective efforts of teachers and students to become conscious about the unequal educational practices existing in their classroom, and to further question and challenge dominant social and educational discourse and their ramifications in the lives of those being educated.

\section{Research Context and Motivation}

A case study is a helpful research strategy to retain the holistic understanding of real-life events and to ask 'how' and 'why' questions that investigate the effects of certain events in a complex social context (Yin, 2003). This study employs the case study methodology to investigate pedagogical challenges and social issues that emerge when implementing CMIC activities in EFL classes, and their educational and social consequences upon students learning and language practices. This case study builds on the author's earlier work (Lee et al., 2016) that developed and integrated a series of CMIC activities in two EFL classes (one in South Korea and the other in Iran). The present author was an English teacher-researcher in the Korean class. Motivated by a desire to innovate her own teaching practice, the author developed a 
Lee, K. (accepted). Implementing computer-mediated intercultural communication in English education: A critical reflection on its pedagogical challenges. Journal of Computer Assisted Learning.

CMIC-implemented EFL teaching framework, the Computer-assisted Multiliteracies Programme (CaMP), utilising a notion of multiliteracies that specifically included English language, cultural, and media literacies (Table 1). The three pedagogical principles embedded in the CaMP were the following:

i) Provide authentic English communication opportunities to EFL students whose everyday communication medium is not the English language;

ii) Introduce English as a tool not for learning native speakers' culture but for intercultural communication to understand diverse cultures in the world;

iii) Expand students' understanding of communication to include multimodal communication practices.

In order to support the CMIC activities between the Korean and Iranian students, an online learning environment was also developed: the CaMP-site (Figure 1). A range of technological tools were either embedded in or linked into the CaMP-site. The initial evaluation of the implementation of the CaMP framework in the two classrooms suggested positive changes in students' English learning attitudes and outcomes. For example, the participating students showed an increased level of motivation for learning English and expressed a clear sense of satisfaction with their CMIC experiences (see more in the following section). Those results were in line with other researchers' positive observations regarding similar pedagogical initiatives (e.g., Liaw \& English, 2017; Villar-Onrubia, \& Rajpal, 2016; Wach, 2015).

However, there were also subtle but negative consequences observed in the CaMP, which were not the focus of the author's initial investigation but which intruded into the data at various moments. For example, implementing the framework in real-life school contexts across two countries was very costly, which made it very challenging for individual teachers to enact the framework in their classrooms. Additionally, and perhaps more seriously, irreducible gaps in students' socio-economic backgrounds produced unequal learning experiences and outcomes among the students in the same classroom. The point of departure of this case study, therefore, is a desire to revisit the original case, and to pay more attention to those consequences. Thus, this article — unlike the previous work that has emphasised the positive results of adopting CMIC in EFL education contexts-illustrates and conceptualises a range of unintended educational effects that receive less frequent attention in the literature. This is not to undermine the claims elsewhere that perceive the implementation of CMIC in language education as broadly 'successful' and 'effective'; but to present an analysis that is both more practically realistic and more conceptually sophisticated than those earlier claims. Thus, for CMIC to be a genuinely 'alternative' approach to EFL instruction, it is crucial to better understand in which ways its implementation changes the more conventional EFL educational practices and, at the same time, in which ways it introduces new 
Lee, K. (accepted). Implementing computer-mediated intercultural communication in English education: A critical reflection on its pedagogical challenges. Journal of Computer Assisted Learning.

issues to EFL education situations.

Table 1. CaMP structure

\begin{tabular}{|c|c|c|c|}
\hline \multirow[t]{2}{*}{ Stages } & \multirow[t]{2}{*}{ CMIC Activities } & \multirow[t]{2}{*}{ Description } & $\begin{array}{l}\text { Internal Tools Embedded in CaMP- } \\
\text { site }\end{array}$ \\
\hline & & & External Tools linked to CaMP-site \\
\hline \multirow{2}{*}{ 1. Introduction } & \multirow{2}{*}{ e-Profile writing } & \multirow{2}{*}{$\begin{array}{l}\text { Individually, writing an online } \\
\text { profile about me }\end{array}$} & Personal page with editing tools \\
\hline & & & Social networking sites: Facebook \\
\hline \multirow{2}{*}{$\begin{array}{l}\text { 2. Individual } \\
\text { Reading }\end{array}$} & \multirow[b]{2}{*}{ e-Text reading } & \multirow{2}{*}{$\begin{array}{l}\text { Individually, reading online } \\
\text { documents about partner's culture }\end{array}$} & Group page with hypertexts \\
\hline & & & $\begin{array}{l}\text { Hypertexts: Wikipedia } \\
\text { Search engines: Google }\end{array}$ \\
\hline \multirow[b]{2}{*}{$\begin{array}{l}\text { 3. Collective } \\
\text { Writing }\end{array}$} & \multirow[b]{2}{*}{$\begin{array}{l}\text { Collaborative media } \\
\text { project }\end{array}$} & \multirow{2}{*}{$\begin{array}{l}\text { Collaboratively, producing media } \\
\text { products about our culture }\end{array}$} & Asynchronous discussion forum \\
\hline & & & $\begin{array}{l}\text { Production tools: Movie Maker } \\
\text { Presentation tools: PowerPoint } \\
\text { Sharing sites: Youtube }\end{array}$ \\
\hline \multirow{4}{*}{$\begin{array}{l}\text { 4. Intercultural } \\
\text { Communication }\end{array}$} & \multirow{2}{*}{$\begin{array}{l}\text { Class-to-class } \\
\text { communication }\end{array}$} & \multirow{2}{*}{$\begin{array}{l}\text { Collaboratively, discussing } \\
\text { differences and similarities between } \\
\text { two cultures }\end{array}$} & $\begin{array}{l}\text { Asynchronous discussion forum } \\
\text { Synchronous chat tool }\end{array}$ \\
\hline & & & \multirow[t]{3}{*}{$\begin{array}{l}\text { Social networking sites: Facebook } \\
\text { Web-conferencing tool: Skype }\end{array}$} \\
\hline & $\begin{array}{l}\text { One-to-one } \\
\text { communication }\end{array}$ & $\begin{array}{l}\text { Individually, discussing differences } \\
\text { and similarities between two } \\
\text { cultures }\end{array}$ & \\
\hline & e-Conference & $\begin{array}{l}\text { Collaboratively, discussing } \\
\text { differences and similarities between } \\
\text { two cultures }\end{array}$ & \\
\hline \multirow{2}{*}{ 5. Reflection } & \multirow{2}{*}{ e-Blogging } & \multirow{2}{*}{$\begin{array}{l}\text { Individually, writing about the } \\
\text { CMIC experiences }\end{array}$} & Personal page with editing tools \\
\hline & & & \\
\hline
\end{tabular}


Lee, K. (accepted). Implementing computer-mediated intercultural communication in English education: A critical reflection on its pedagogical challenges. Journal of Computer Assisted Learning.

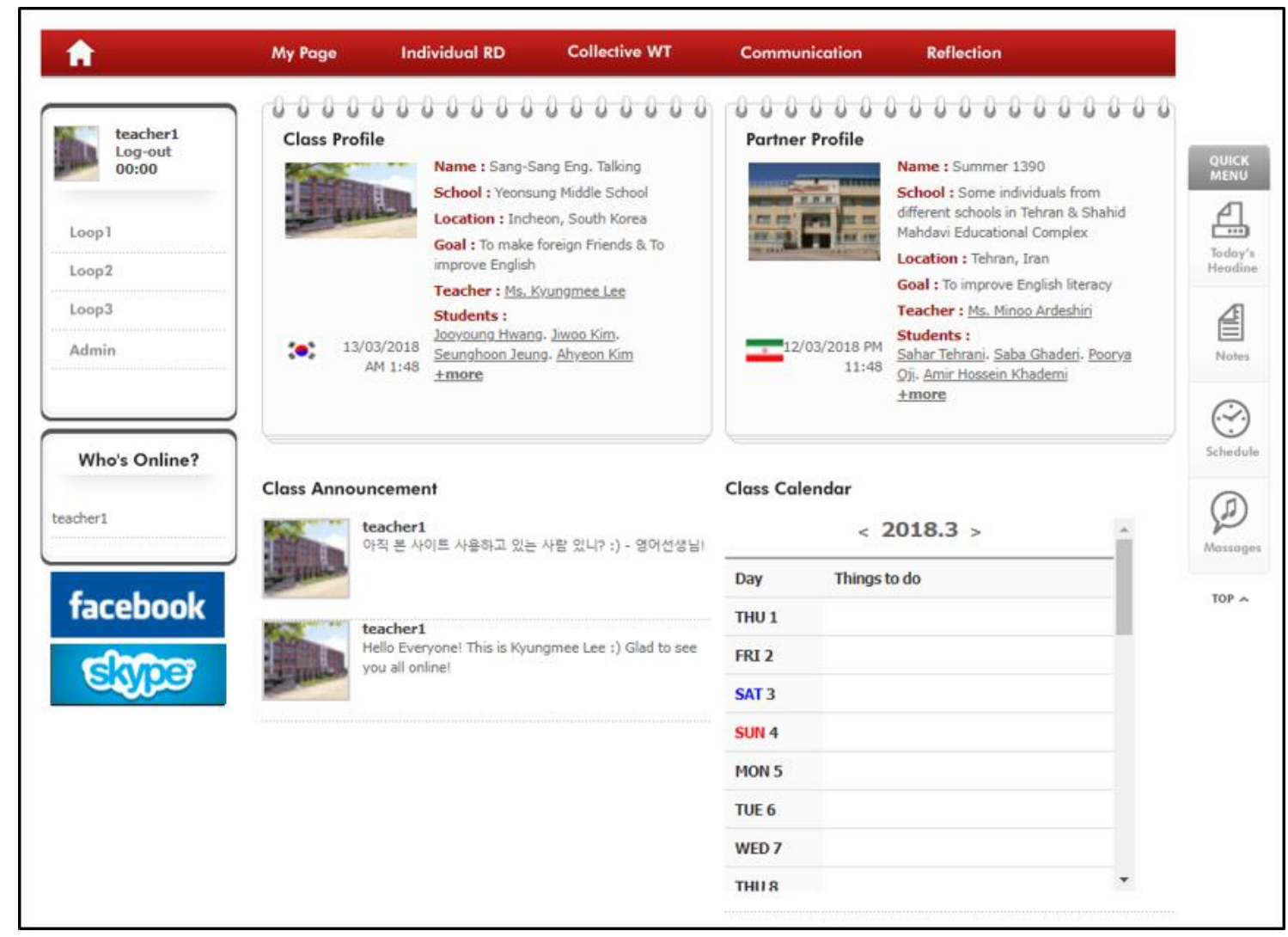

Figure 1. An Interface of the CaMP-site

\section{Previous Study}

In order to better situate the present case study in its original real-life context, this section provides a brief summary of the findings from the previous qualitative case study that mainly focused on positive aspects of students' learning experiences in the Korean EFL class.

\subsection{Participants}

As a teacher-researcher, the author designed and taught a three-week-long English course utilizing the CaMP framework in a Korean public middle school at which she was teaching English. An Iranian EFL teacher-researcher, a colleague of the author from the same doctoral program in Canada, and her thesis supervisor, a well-known second language educator, participated in the original research project and supported the implementation of the CaMP in the two EFL classes. Twenty-three Korean students voluntarily registered for the course and agreed to participate in the project. Informed consent from their parents and the school principal about their participation in the research project was also obtained. All student participants were in grades 7 to 9 (aged 13 to 15). Although the level of English among students 
Lee, K. (accepted). Implementing computer-mediated intercultural communication in English education: A critical reflection on its pedagogical challenges. Journal of Computer Assisted Learning.

was varied, most students were at a beginner level. Over the three weeks, the Korean class met every day from Monday to Friday for a two-hour session, with a ten-minute break in the middle. The class was virtually connected to the Iranian partner class through the CaMP-site. In the partner class, twenty-two individual Iranian students (aged 14 to 15), attending different schools but located in the same neighbourhood, were recruited. The Iranian teacher-researcher first recruited a class of seventeen Iranian female students from her school, a private female middle school in Tehran. Subsequently, she recruited five more male students through her personal contacts with their families.

Table 2. Student Participants

\begin{tabular}{|c|c|c|c|}
\hline \multicolumn{2}{|c|}{ Korean Students $(\mathrm{N}=23)$} & \multicolumn{2}{c|}{ Iranian Students $(\mathrm{N}=22)$} \\
\hline Female & Male & Female & Male \\
\hline 14 & 9 & 17 & 5 \\
\hline
\end{tabular}

\subsection{Data Sources}

Data was collected from multiple sources. Yin (2003) suggests that it is important to collect multiple data sources and to provide a detailed case description for a qualitative case study, particularly when the study focuses on a single case. The most important data source was the author's field notes, in which she chronologically recorded the entire process of designing and teaching the CMIC-implemented English course.

While designing and preparing the special summer course, the author was also teaching four regular Grade 9 English classes at the same middle school. Each class had approximately twenty-five students. Their learning behaviours and attitudes were also recorded in order to produce more comparative understanding about students' experiences in the CMIC-implemented English course. While teaching the three-week-long CMIC-implemented English course, the author closely interacted with the twenty-two student participants and observed their behaviours and attitudes in the daily sessions. Immediately after each session, the author had a Skype conversation with the Iranian teacher-researcher each day. The two teacher-researchers shared their experiences, thoughts, and feelings, discussed some of the issues noticed, and considered different courses of action that could be taken to address the issues. Additionally, the author wrote a daily journal entry recording the students' behaviours and attitudes in each session and the follow-up conversations with the Iranian teacher-researcher. Even though there were no formal interviews conducted, the author continued to have informal conversations with the student participants and two other English teachers at her school throughout the course: those conversations were also recorded in the author's field notes. 
Lee, K. (accepted). Implementing computer-mediated intercultural communication in English education: A critical reflection on its pedagogical challenges. Journal of Computer Assisted Learning.

The second major data source was Korean students' responses to the course evaluation questionnaire, which included six open-ended questions about their English learning experiences in the CMIC-implemented English course. The questions posed were as follows:

- How would you describe your experiences in this summer English course?

- In general, what do you think about this summer English course?

- In general, what do you think about learning English?

- What were the most valuable aspect(s) of the course?

- What were the least valuable or the most difficult aspect(s) of the course?

- What are your future plan(s) about English learning?

These two sets of written texts were initially analysed using constant comparative methods (Strauss \& Corbin, 1990). Three dimensions of the initial coding schemes consisted of acting subjects (teacher, student and group), the five stages of the CaMP framework, and the seven CMIC activities in the framework (see Table 1). The coding results were discussed with, and member-checked by, the Iranian teacher-research and her doctoral supervisor; and the results were subsequently revised. Other class artifacts, including student learning outcomes, video clips, discussion threads, and chat records, were also collected and used for the additional data triangulation process (see Golafshani, 2003).

\subsection{Results}

The detailed description of students' experiences and perceptions in the CMIC-implemented EFL classes can be found in the previously published article (Lee et al., 2016). This section recapitulates how Korean students' learning experiences in the CMIC-implemented English course differed from ones in a more traditional English class.

\section{1) Instructional focus: Grammar-translation vs. Communication}

The regular English class at the participant Korean school mainly consisted of grammar lectures and reading-and-translation practices lacking in communicative approaches to language learning as other researchers have previously reported about many EFL classes (e.g., Butler, 2011; Coskun, 2011; Jeon, 2009; Wong, 2012). The learning content was entirely provided by a teacher, while students remained silent throughout a 45-minute session (four sessions per week) except when responding to teacher's closed-answer questions. Many students seemed to have difficulties in fully concentrating on the teacher's lecture and a few students were dozing off or texting (doing something with their mobile phones). Although each unit of the English textbook used did include some activities meant to support 
Lee, K. (accepted). Implementing computer-mediated intercultural communication in English education: A critical reflection on its pedagogical challenges. Journal of Computer Assisted Learning.

communicative action, in reality what was observed tended to be rather mechanical and based on the prescripted conversations with little deviation. Due to the large volume of subject content that each session was required to cover, the teacher found it difficult to allocate sufficient time to the communicative activities, which doubtless constrained the exploratory nature of students' conversations.

On the other hand, the CMIC course, which was virtually connected to the English class in Iran, chiefly focused on communicative activities. Each Korean student was paired with an Iranian student (or two Iranian students) as a conversation partner and the pair exchanged cultural information and knowledge using the English language. Each student prepared and led their conversations with Iranian students according to their own interests, without the teacher's direct intervention. Students showed genuine enthusiasm and excitement about the course structure that provides opportunities to meet and interact with "foreign friends". This was clearly shown in the students' course evaluation results (see details in Lee et al., 2016). All twenty-three Korean students initiated the online conversations at least twice during the three week period. Except for 1 student who had a health problem, all twenty-two students were actively engaged in and contributed to all of the communicative activities despite the voluntary nature of the participation in this summer class.

\section{2) English: school subject vs. intercultural communication tool}

In the regular English class, students' learning achievement was evaluated exclusively based upon the accuracy of their responses to multiple-choice or short-answer questions in written exams. In this context, English tended to be perceived by many students just as one of the academic subjects that they need to study for getting a good score on those paper exams (see Kim, 2013 and this is also indicated in the students' responses in the course evaluation). However, participating in a series of CMIC activities effectively changed the common perception of English among EFL students—from a piece of knowledge including grammatical rules and lexical items often distant from their real-life communication practices to a communication tool that enables them to interact with people in other cultural contexts and so to learn about other cultures. In fact, most of Korean EFL students in the course ( $\mathrm{N}=17$ out of 23) mentioned, in the course evaluation questionnaire, that talking to Iranian students increased their motivation to improve their English communicative competence as a mean of learning more about other cultures.

In the collective writing stage (See Table 1 above), Korean students as a group produced videos about different aspects of Korean culture to introduce Korea to their Iranian partners: each group focused on i) popular Korean food, Kimchi, ii) traditional Korean clothing, Hanbok, iii) Korean pop music and singers, iv) travel information about Korea's capital, Seoul, and v) Dokdo Island, a territory whose 
Lee, K. (accepted). Implementing computer-mediated intercultural communication in English education: A critical reflection on its pedagogical challenges. Journal of Computer Assisted Learning.

ownership is subject to dispute between Korea and Japan. Korean students also watched a series of videos about Iran produced by Iranian students, which generated interesting discussions about the differences and similarities between Iran and Korea. The Korean class, then, invited the Iranian teacher via Skype to ask further questions about Iran and Iranian culture. This "e-Conference" activity was led by the Korean students who asked a list of prepared questions, with some linguistic support of their teacher, about particular aspects of Iranian culture, which are "shockingly strange" (students' expression). For example, Korean students wanted to know why female and male students in Iran cannot attend the same school or have direct conversations. Another interesting question was about whether Iranian women are allowed to wear jeans and short skirts in public. Here, all students became active learners of Iran's culture and fully engaged in the CMIC that was fundamentally guided by their own inquiries.

\section{3) Communication: linguistic practices vs. multimodal practices}

Unlike the regular English class in the Korean school that focused exclusively on English literacy (i.e., how to read and write print-based texts), the CMIC course provided students with various channels and digital media for communication. Korean students participated in a series of "Intercultural Communication" activities with their Iranian partners (and the teacher) using CMC technologies and social networking tools (e.g., chat tool, Skype), while students were also engaged in e-Text reading activities to search and learn about Iran and Iranian culture (e.g., hypertexts, Wikipedia, Google). In particular, for the collaborative media project that aimed to introduce Korean culture to Iranian students, each group of the Korean students chose a topic, collected the required information and visual resources, and created a short video clip - using multiple means to present and communicate their ideas with others (e.g., Movie Maker, PowerPoint). By experiencing these multimodal communication practices, students were able to expand their previously narrowly constructed understanding of English literacy to encompass media literacy.

It will be useful to illustrate this matter using an example. Han, a fifteen-year old male student, had relatively low English communicative competence and learning motivation: in the informal conversations with the teacher he openly stated that it was his mother who had forced him to register to the course despite his lack of interest in learning English. At the beginning of the course, it was noticeable that he was not enthusiastic about writing his online profile nor talking with his assigned Iranian conversation partner. At the end of the first week, the class moved to the computer lab to search and read e-text about Iran. Initially, the students used domestic Korean search engines with Korean search terms and retrieved only a small amount of search results - there was, in fact, not much pertinent information (about Iranian culture) available in the Korean language. Subsequently, it was Han who searched resources using global 
Lee, K. (accepted). Implementing computer-mediated intercultural communication in English education: A critical reflection on its pedagogical challenges. Journal of Computer Assisted Learning.

search engines (e.g., Google and Yahoo) and thereby retrieved a large number of images and video produced in different languages (largely in English and Persian). Those images and videos portrayed popular culture in Iran, in which the class showed a great interest. Han also used, and encouraged his peers to use, Google Translate to understand what the searched images referred to. He actively engaged in the collaborative media project, through which he made meaningful contributions to developing the group presentation by collecting various media resources and editing the video. For his part of the video presentation, he proudly mentioned later to the teacher, he had practiced reading the presentation script more than 10 times and said that this was the first time for him to make an effort to learn English. Although, from the traditional linguistic perspective, there was no remarkable improvement in his English communicative competence during the relatively short period of the course, he showed a great deal of positive change in his attitude toward English communication, which he came to increasingly see as a set of multimodal practices.

\section{Present Study}

The present case study is qualitative and explanatory, focusing on a single case of the Korean CMIC-implemented English class (Yin, 2009). It revisits the previous case and re-examines the previously collected and analysed data sources but using a different theoretical perspective - the principles of multiliteracies and critical pedagogy set out in section 3 .

\subsection{Data Re-analysis}

The present study aims to develop a deeper understanding of the course of events observed in the case and their social effects upon EFL learners and learning, which were not highlighted sufficiently in previously published accounts. This explanatory case study is based on the paradigm of critical educational research, which has emerged from recognising the critical limitations of both positivist and interpretivist paradigms. Those paradigms both often neglect (or underemphasize) the political and ideological conditions of many educational contexts (Gage, 1989). In contrast, the paradigm of critical educational research, heavily influenced by Critical Theory, sees educational research as a deliberately political activity aiming to reveal unequal social and educational conditions, to empower students to take control of their learning conditions, and to bring about transformative changes in schools (Cohen, Manion, \& Morrison, 2011). This paradigm has directly informed my selection of i) a theoretical framework that guides my meaning-making process about the educational phenomenon under investigation and ii) the critical events within the focused case.

Acknowledging the difficult nature of qualitative research in terms of demonstrating its reliability 
Lee, K. (accepted). Implementing computer-mediated intercultural communication in English education: A critical reflection on its pedagogical challenges. Journal of Computer Assisted Learning.

and validity, this case study utilized the concept of 'critical friends' for ensuring the 'trustworthiness' of the research outcomes (Lincoln \& Guba, 1985). The author first re-analysed the data and drew some preliminary findings about the pedagogical challenges and social issues experienced by EFL teachers and students in the CMIC-implemented course. The two other Korean English teachers at the participant school reviewed my findings and made some suggestions, which have been all incorporated in my results section below. The Iranian English teacher-researcher who taught the Iranian partner class was also invited to be a third reader of the results in the member-checking process. Next, the author developed tentative theoretical explanations about those challenges and issues utilizing the selected theories. To sharpen (or validate) the explanations and explore a more effective approach to adopting the CMIC activities in EFL class, the author had an in-depth conversation with the two Korean English teachers again after writing an initial version of the account presented in this paper, particularly focusing on the feasibility and the applicability of the arguments made to their own teaching practice. The following 'Results' section will focus on the pedagogical challenges and social issues that were observed and identified in the CMIC-implemented course. The 'Discussion and Implications' section will offer some theory-informed pedagogical principles that, it is argued, may guide other EFL teachers' effective adoption of the CMIC activities in their classes.

\subsection{Results}

Regardless of the careful design and planning of the CMIC activities in the course, the implementation of such courses brought about numerous pedagogical challenges in the Korean class. Diverse issues of inequality, while not necessarily new or directly created by the implementation of the activities, were revealed and made more salient in the course as compared with the traditional classes. In the following section, a few examples, coming out of the author's secondary analysis of the collected data based on the analytic lens explained in the previous section, are provided.

\section{1) Pedagogical challenges and a high cost of its implementation}

To begin with, one of the critical challenges that most EFL teachers would face when implementing the CMIC activities in their classrooms is perhaps related to its high cost in terms of the required level of teacher's cultural and social capital as explained below. One of the essential components of this course was to connect the Korean class with Iranian students, which was mainly based on the two teachers' international connections. It would not be possible for individual EFL teachers in Korea without such a close contact with other teachers in different cultural contexts to implement such pedagogical initiatives in their classrooms. Additionally, but more fundamentally, such intercultural collaborative teaching, 
Lee, K. (accepted). Implementing computer-mediated intercultural communication in English education: A critical reflection on its pedagogical challenges. Journal of Computer Assisted Learning.

between EFL classes across two or more cultural contexts, requires teachers to possess a high level of cultural capital (or linguistic capital: that is, a sufficient level of English communicative competence). It should be noted that the author, Korean teacher, in this study possesses a much higher level of cultural capital, fundamentally gained from her relatively privileged educational and socio-economic background $^{2}$, than the average level of capital that EFL teachers in Korean public schools have. Previous studies, in fact, suggested a large group of EFL teachers struggled with their low level of English communicative competence when applying a communicative language teaching approach in their classrooms (see Butler, 2011; Li, 1998; Nunan, 2003).

Secondly, despite the relatively high level of the author's capital, there were a number of contextual problems which significantly hindered the effective implementation of the course. Some of those contextual problems are institutional, such as irreconcilable differences between the Korean and Iranian class sizes and academic calendar. Yet a number of the contextual problems are more subtle and less predictable, implicating social and cultural constraints.

One example is that right before the course started, the administrators of the Iranian female school raised concerns about their female students being in 'direct contact' (even if that contact was virtual) with male Korean students. They would not allow the course to be implemented unless this issue could be addressed. Thus, the Iranian teacher had to recruit individual students from outside the participating school, in order to facilitate pairing the nine male Korean students to Iranian students as one-to-one conversation partners. Even with these arrangements in place, managing some of the class-to-class communication tasks in ways that prevented direct contact between female students in Iran school group and the nine Korean male students required time-consuming management effort. Another significant example relates to the low level of some Iranian students' participation in the CMIC activitiesparticularly those with religious family background. The course was implemented in Iran just before the Ramadan period (the ninth month in Muslim calendar, which is considered the holy month), and so some families embarked on a spiritual trip, during which participants lacked internet access, or otherwise restricted their children's social and academic activities, including those using CMC tools. A couple of Korean students who had not received prompt responses from their Iranian partners for these reasons, showed a significant level of frustration and dissatisfaction with the course; nevertheless, the Korean teacher could not do much about this problem.

\footnotetext{
${ }^{2}$ She has earned her graduate degree from a Canadian university and has several years of living experiences in English speaking countries while most Korean EFL teachers have a bachelor's degree from Korean universities as their highest degree without having substantial experiences or contacts outside Korea.
} 
Lee, K. (accepted). Implementing computer-mediated intercultural communication in English education: A critical reflection on its pedagogical challenges. Journal of Computer Assisted Learning.

Another example occurred when the Korean students uploaded their video clips to YouTube. At that point the Iranian government unexpectedly blocked the public access to the YouTube site as part of ongoing Internet censorship practices. Although the Iranian teacher sent out the video files to each student by email instead, due to the slow download speed in Iran, both the Iranian teacher and students experienced significant inconvenience. Also, the originally expected student interactions on the YouTube site, using that site's "comments" features, did not take place. This limitation in access to the learning materials and environment also significantly decreased the Iranian students' learning motivation and participation. Although students in both classes expressed great interest in meeting foreign friends and learning about each other's culture, leading those interested students towards active participation in the communication activities and supporting meaningful CMIC experiences was not a straightforward process for the teachers. Thus, it can be argued that the cost of implementing the intercultural communication activities in the actual classroom settings is high, which requires a sufficient level of teachers' social and cultural capitals and their thoroughgoing commitment to the course including considerable personal time and effort to innovate or change teaching practices. 2) Issues of unequal cultural capitals among students

Even though most students were active throughout the course, it would not be accurate to conclude on that basis that all students equally participated in and benefited from the authentic English communication opportunities provided in the course. There were pre-existing gaps in the cultural (or linguistic) capital that each student brought with them to the course, and such inherent socio-economic inequalities in the actual social schooling context were reflected in, as well as influential upon, each student's learning practices and outcomes in the CMIC. Transferring the instructional focus from grammar-translation to communication, in ways that required students to be active English speakers, in fact, made the disparity in students' English language proficiency more salient in the course than within the regular English classes.

The following two cases may effectively demonstrate how such disparity in students' linguistic capitals influenced their learning attitudes and outcomes in the course.

One fourteen-year old female student, Min, had been sent by her parents to Australia during her primary school years, mainly for the purpose of learning English. Min had also been taking private English lessons since her return to Korea. On the other hand, another fourteen-year old male student, Jang, had never had actual English speaking opportunities prior to the course. In his informal conversation with the teacher, he implied that that was mainly because his family was not able to afford any costly private English education offering actual English speaking opportunities (e.g., a small group 
Lee, K. (accepted). Implementing computer-mediated intercultural communication in English education: A critical reflection on its pedagogical challenges. Journal of Computer Assisted Learning.

tutoring by a foreign teacher, a study-abroad programme). Min, from the beginning of the course, showed great enthusiasm for the series of intercultural communicative activities, whereas Jang rarely expressed his own ideas and remained quiet throughout the course. Min was a member of the group that produced a video clip about political issues related to Dokdo Island, which was the most complicated topic among the five chosen within the class, and she took the leading role in her group. In contrast, Jang took a rather passive role in his group, which produced a video clip about Korean pop music and singers: he introduced his favorite singer using a few simple English sentences.

While Min was able to have meaningful conversations with her Iranian partner, Jang was only able to use the opportunity to exchange simple greetings and superficial information about Korea and himself with his partner. These differences between the two students' CMIC experiences in the course reflected the considerable gap between their levels of English communication competence, in this case a product of their different cultural capitals, and it was certainly not an easy task for individual teachers to address. Therefore, it is difficult to claim that adopting CMIC activities actually offered an "equal" access to communication opportunities to students at all levels. Each student's learning experiences in this course was fundamentally influenced by the extent of cultural capital that each of them had brought into the course from outside.

\section{3) Issues of an unequal process of subjectification of a good student}

If one simply adopts a (social) constructivist approach to teaching and evaluation, the answer to the question "who are the good students?" in the intercultural communicative course clearly differ from the ones in the regular, or more common, EFL classes. In other words, in the new course, active participants in the given communicative tasks are considered as "better students" than those passive listeners. In the regular EFL classes, receptive learning behaviours such as listening to teachers, taking notes, and reading textbooks silently are rewarded as legitimate classroom behaviours, whereas, active and self-directed or self-expressive behaviours (e.g., discussing, creating, and sharing) are more valued and rewarded in the intercultural communicative course.

It is important to note that that distinction is not merely an external, analytical point. The differences in legitimate student behaviours in the two classrooms were reflected in the language used by the teacher in each setting. At the most basic level, it is common to observe in the regular classroom, teachers saying "be quiet" or "listen carefully" while in the communicative course, the teacher continued to ask her students to "be active" or "speak up". Nonetheless, despite this shift in classroom norms or desired behaviours, it was noted that those active participants in the communicative course were, in fact, 
Lee, K. (accepted). Implementing computer-mediated intercultural communication in English education: A critical reflection on its pedagogical challenges. Journal of Computer Assisted Learning.

the same students who were considered good in the regular English classes. Regardless of the change of the instructional discourses, the students who followed the appropriate class norms and behaved accordingly were more positively perceived by teacher (or institution, which is a school in this case) than the students who did not in both discursive contexts. Going back to the two student cases discussed above, it was a certainly the case that Min was doing much better even in the regular English class as well as on her exam than Jang. The difference was more salient in the case of Jang whose learning behaviours (e.g., being quiet) were not perceived as problematic and bad in the regular class ${ }^{3}$, whereas it was clear that he was not (or more likely, not able to be) a good student in the communicative course without having a certain level of English communicative competence.

It may be also important to note that, in the third stage of the course, the collective writing (see Table 1) students with similar levels of English communicative competence spontaneously formed groups together for the collaborative media project. As a result, unequal cultural capitals were distributed among the five groups and subsequently, the complexity of the topic each group selected and the quality of each group's outcome tended to correspond to the level of its members' cultural and linguistic capitals. A more striking difference among the five groups was in the quality of their collaboration processes. For example, whereas students in the Dokdo group, to which Min belonged, seemed to know exactly how to collaborate on the project not only effectively but also efficiently, the group that dealt with the least complex topic (i.e., Korean traditional food Kimchi) continually consulted with the teacher on what to do. Inevitably, the students in the former group were more engaged in the whole learning process and produced a better outcome than the latter group - the gap was significant.

This difference, again, indicates that each student possessed an unequal level of cultural capital referring to certain forms of academic skills and communication or collaboration abilities that were less likely taught in the traditional education settings. Despite the fact that the teacher was conscious of the different levels of prior knowledge and skills with which each group started their project, she was not able to give all groups the same grade but had to give the Dokdo group students higher grades. In the communicative course, the inequalities among Korean students related to different socio-economic backgrounds that each of them came from tended to be reinforced by the new set of learning norms and expectations for being a good student. 4) Issues of the unequal status of English speakers and the unequal formation of students' linguistic identities

It should not be denied that EFL students as active participants in the course clearly had more

\footnotetext{
${ }^{3}$ In fact, Jang's exam grade was in the middle range: his average grade in English subject was B.
} 
Lee, K. (accepted). Implementing computer-mediated intercultural communication in English education: A critical reflection on its pedagogical challenges. Journal of Computer Assisted Learning.

opportunities to express their thoughts, interests and needs compared to other EFL students in the regular classes where those opportunities were rarely available in the first place. Sue, a fourteen-year old female student with an extremely outgoing and bright personality, was one of the students who had often been admonished by her teacher for her bad classroom behaviours (e.g., not concentrating on the teacher's lectures, chatting, texting, etc.) in the regular English classrooms where she had never been given a chance to vocalize her ideas. Although she was not necessarily a good student in terms of her academic achievement $t^{4}$ or classroom behaviours, she certainly was very popular among her friends. In the communicative course, Sue initially showed a great level of excitement about talking to her Iranian partner and working on the collaborative media project. She did not only actively participate in but led the classroom discussions and shared lots of interesting ideas and well-received suggestions throughout the course. For example, to introduce Korean traditional clothing Hanbok more effectively to Iranian students, she brought her own Hanbok and videotaped herself and her group members wearing Hanbok. She repeatedly came to the teacher to request for diverse supports (e.g., using a school i-pad and accessing to an empty classroom, proofreading their English script, etc.).

It might be expected that such active and self-regulated learning experiences would empower students to fully exercise their autonomy in their learning processes, and possibly thereby enable them to overcome or at least partially ameliorate their differences in cultural capital. In other words, more autonomous and motivated students might potentially liberate themselves from their prior constraints and improve their educational and living conditions. The transformative nature of the attitude changes that Sue showed in the communicative course and subsequently, the positive changes of teacher perception on her as an active (and therefore 'good') student was expected to be an instance of that phenomenon: empowering students and potentially liberating them from the marginalisation function of schooling.

However, a couple of days after her group's video was uploaded online to be shared with Iranian students, Sue asked the teacher to remove the video because she felt embarrassed about the strong Korean accent in her English speech in it. She directly said: "my English sounds stupid! It does not sound like English at all." She also compared her accent with the accents of other students who had gone abroad to learn English; she clearly perceived that their accent more closely resembled the 'ideal' than her own. Although there was subsequently a classroom discussion about the Iranian students and teacher's accent, which encompassed the idea of English as a global language that needs to be more inclusive about diverse forms and accents (rather than viewed normatively in light of American or British accents), Sue remained

\footnotetext{
${ }^{4}$ Sue's exam grade was in the middle range: her average grade in English subject was B.
} 
Lee, K. (accepted). Implementing computer-mediated intercultural communication in English education: A critical reflection on its pedagogical challenges. Journal of Computer Assisted Learning.

upset about her "Korean accent" which she persisted in perceiving as inferior.

When it comes to the formation of EFL students' linguistic identities, the unequal status of English speakers in the broader EFL context seems to play a more powerful role in the process than the actual quality of students' performances in the communicative course. Similarly, the prevalent idea of 'native English' as some sort of gold standard among students remains difficult to challenge and deconstructjust as Sue stubbornly refused to accept her Korean accent as a legitimate English accent. In this case, it is difficult to argue that she fully exercised her autonomy in resisting the negative social meaning attached to non-natives' English and constructing a positive linguistic identity of herself, despite her active participation in the CMIC activities.

\section{Discussion and Implications}

The adoption of CMIC activities certainly provided authentic English communication opportunities to Korean EFL students, introduced the idea of English as a tool for intercultural communication to learn other cultures, and effectively expanded students' understanding of communication to include multimodal practices. Thus, this new approach, in general, can be a promising alternative to more traditional forms of classroom-based EFL education, one which may effectively address some of the pedagogical challenges that are repeatedly identified in the literature on traditional EFL contexts. However, such adoption also introduced different pedagogical challenges and actually made some of the social issues of inequality in EFL contexts more salient. It is, therefore, necessary for teachers, instructional designers, and educational researchers who attempt similar pedagogical initiatives in language education contexts to be aware of those issues; they may have subtle but negative impact on students' learning outcomes and identities, in particular for students who are already socially and economically disadvantaged. In other words, the CMIC activities should be implemented in language classrooms in more pedagogically, socially, and culturally sensitive ways that aim to reduce the negative educational effects of its adoption. In this discussion section, therefore, the author seeks to address the obvious question: how can we conceptualise what those 'more sensitive ways' might actually look like?

To address that question, three teaching and instructional principles are proposed, drawn in turn from the two closely interrelated theories outlined earlier: Multiliteracies Pedagogy and Critical Pedagogy. Mostly fundamentally, the author argues that the effective adoption of the CMIC activities needs to be a theoretically informed practice, which is critically and clearly guided by those principles. The principles, which will be elaborated in turn below, are: to set up a political goal for such adoption; to identify and prepare for 'teachable moments' during the activities; and to create new discourses, norms 
Lee, K. (accepted). Implementing computer-mediated intercultural communication in English education: A critical reflection on its pedagogical challenges. Journal of Computer Assisted Learning.

and teacher language that operate alongside the pedagogical initiatives.

\subsection{Set up a political goal of the pedagogical initiatives}

The first principle requires teachers not to be naïve actors serving the unequal schooling mechanisms by uncritically exercising their pedagogical power upon students but to be transformative intellectuals ${ }^{5}$ who make "the pedagogical more political and the political more pedagogical (Giroux, 1988, p. 127)."

Conceptually speaking, the first step towards becoming a transformative intellectual is to be aware of social and cultural inequalities in the education context, including the issues discussed in the previous section and recognise the struggles that disadvantaged students experience in the EFL educational settings. The second step is to develop a self-image as a political actor who critiques and changes (or improves) the unequal educational conditions to alleviate the issues of inequalities and reduce the reproduction power of education. The third step is, then, to educate and empower students to also become political actors who contribute to the development of a more equal and less oppressive future. It may be necessary for teachers to have a solid theoretical ground, which can effectively guide their reflective practices, involving a complicated — certainly not so straightforward - course of action. This article suggests that critical pedagogy can offer effective guidance for that praxis.

According to Burbules and Berk (1999), critical pedagogy is an effort "to raise questions about inequalities of power, about the false myths of opportunity and merit for many students, and about the way belief systems become internalized to the point where individuals and group abandon the very aspiration to question or change their lot in life" (p. 50). Critical pedagogy, in fact, originally emerged from the context of literacy education aiming to foster "learning to perceive social, political, and economic contradictions, and to take action against the oppressive elements of reality (Freire, 1995, p. 17). On that basis, "reading the world" through literacy practices such as reading and decoding "texts" is a central strategy of critical pedagogy (Freire, 1998). In this sense, both the political aims and pedagogical strategies offered by critical pedagogy can be useful for the EFL teachers when implement the CMIC activities in their classroom. Of courses, taking up this theoretical approach would neither immediately remove some of the pedagogical challenges in the course nor directly reduce the cost of its implementation. However, this will enable teachers to perceive one's pedagogical praxis as a political

\footnotetext{
${ }^{5}$ Transformative intellectuals "combine reflection and action in the interest of empowering students with skills and knowledge needed to address injustices and to be critical actors committed to developing a world free of oppression and exploitation (Giroux, 1988, xxxv)."
} 
Lee, K. (accepted). Implementing computer-mediated intercultural communication in English education: A critical reflection on its pedagogical challenges. Journal of Computer Assisted Learning.

action based on moral commitment to students' well-being and consequently, to set up a political goal of implementing such initiatives in a personally meaningful way, which may compensate some of their effort in the course. Furthermore, engaging in academic discussions among critical pedagogues in the similar education contexts can also be helpful for teachers to develop a sense of community or solidarity and further collaborative practices, which can be particularly beneficial (or even essential) to implementing such initiatives.

\subsection{Focus on and be prepared for teachable moments for overt instruction}

The second principle is closely linked to one of the four factors (or pedagogical strategies) that constitute multiliteracies pedagogy: overt instruction ${ }^{6}$. According to the New London Group (1996), in a multiliteracies learning process, teachers need to provide active interventions at "teachable" moments to help students to gain conscious awareness and control over what is being learned and how it is learned. Through meaningful interactions with teachers (or experts), students can denaturalise some of the takenfor-granted social and cultural beliefs and practices, which may have negative impact on their life, thereby opening them up for further critique and challenge.

The results of this case study actually demonstrate that, in retrospect, there were a great number of teachable moments in which the author, Korean teacher, could have more meaningfully intervened in her students' learning and reasoning processes - thereby engaging the students in more reflective and critical dialogues about language, culture, and educational and social issues of inequality. For example, in Sue's case, it might have been useful for the teacher to more proactively identify teachable moments for initiating discussion about the meaning and the importance of "native speakers' English" (and different natives' and non-natives' accents) on intercultural communication practices. Furthermore, rather than simply imposing new classroom norms (e.g., being active and speaking up) on students, it might have been more fruitful, at the beginning of the course, to have open conversations with them about their personal aims of learning the English language, their perceptions of the value of doing so for their life, and the norms that are desirable in the course. In this way, the notion of multiliteracies could be more effectively and meaningfully introduced to, and unpacked by, the students themselves. At the same time, establishing a shared understanding of the fact that there is a great diversity among class members-in terms of their reasons for learning English, the values of English language for their personal life, and their current level of English communicative competence - could be a strong basis for seeding ongoing

\footnotetext{
${ }^{6}$ The New London Group (1996) proposes four essential factors to define a Pedagogy of Multiliteracies: Situated practice, overt instruction, critical framing, and transformed practice.
} 
Lee, K. (accepted). Implementing computer-mediated intercultural communication in English education: A critical reflection on its pedagogical challenges. Journal of Computer Assisted Learning.

discussions about some of the social issues of inequality that become evident throughout the course.

Using such overt instruction strategies seeks to engage students not only in their own learning processes, but also in the teacher's teaching or classroom management processes. Doing so can be also promising in this particular pedagogical context where the teacher tends to face various challenges that are less common in the regular EFL classrooms, and whose solutions might therefore not from the part of their established repertoire. For example, when the government of Iran prohibited the public (including the Iranian students in the course) from accessing the YouTube site, the author could have invited her Korean students to discuss that event, through which the students may be able to think about important notions such as freedom of expression and the censorship of media. In addition, inviting them to become part of the problem solving process - to figure out how to share the videos with Iranian students and have a further discussion with them-would have helped the students to become more active participants and potentially reduced the teacher's burden of implementing the course. We have already seen some meaningful changes in the earlier case of Han who led the classroom practices of using global search engines.

Another critical teachable moment that might be seen as inviting the teacher to more directly intervene, arose when students were forming the groups for their collaborative media projects. That intervention might focus on the equal distribution of cultural capital: the distribution not only of linguistic competence but also of other skills that the students have, into the five groups. Explicit discussion about possible ways of forming the groups so that everyone might have more meaningful and potentially fair learning experiences within course might be also useful in such a situation-useful not only for group formation, but for encouraging students to reflect upon their subsequent actions within the groups.

It would be a challenging task for teachers to intervene in students' learning at all the right moments throughout the course without the benefit of hindsight. That is because of the organic nature of this course, which does not have a fixed curriculum that prescribes what and how knowledge and skills need to be transmitted to students, and the sensitive and political nature of the topics (e.g., social and cultural issues). Therefore, in conjunction with what the first principle suggests, it is necessary for teachers to be prepared for those teachable moments by developing their own cultural and social awareness, appropriately sensitive yet effective language for articulating and unpacking different issues of inequality, and pedagogical strategies to engage students in critical dialogues without excluding anyone or any group in the classroom.

\subsection{Create new discourses, norms, and teacher language}


Lee, K. (accepted). Implementing computer-mediated intercultural communication in English education: A critical reflection on its pedagogical challenges. Journal of Computer Assisted Learning.

The fundamental aim of critical pedagogy is to empower students to challenge and deconstruct dominant discourses (i.e., legitimate knowledge, rules, and subjectivities) and so, ultimately, to denaturalise and disrupt unequal social or institutional structures and power relations. Similarly, in multiliteracies pedagogy, students are expected to transform cultural practices: through participating in personally meaningful multiliteracies practices and through critically examining their own practices in relation to larger social and cultural contexts. The implication is that teachers, as transformative intellectuals, need to create — or at least contribute to creating — new discourses and norms in their school settings.

The third principle focuses on how teachers in the course can approach and fulfill this seemingly challenging and overwhelming task within their classroom teaching praxis. The most essential condition for teachers when approaching this challenge is that they are critical about their own pedagogical beliefs which are, inevitably, to some extent influenced by the dominant discourses in their social, historical and educational contexts. In particular, when it comes to the construction of students' subjectivities (and their own subjectivities as a teacher), the teacher should strive to avoid asking simple questions such as "who is a good or bad student?" or "who is active or passive?". Instead, an attempt should be made to ask more critical questions such as "who may be perceived as a good or bad student?", “why or why not?", or "who may benefit or be disadvantaged by the assessment criteria in operation?" Asking those questions may effectively reveal, at least to teachers themselves, some of the hidden social mechanisms of schooling that serve to reproduce hegemonic power relationships among students with unequal socio-economic status.

At the practice level, then, teachers can use this insight as one basis for critically evaluating the dominant forms of classroom language, which often contain common sense assumptions about schooling, teaching, learning, achievement, teacher-student relations, etc. (Giroux, 1988). Language is not a valuefree or neutral instrument, which simply conveys individual users' ideas or objectively represents social realities. Instead, it is both a value-laden political product and a tool, which mostly serves dominant cultural groups by circulating and reinforcing certain social beliefs and by influencing and changing people's thoughts and behaviors (see Woolard \& Schieffelin, 1994). Therefore, teacher's classroom language needs to be an object of critical examination, through which teachers can continuously revisit and revise one's pedagogical beliefs and assumptions. Based on the examination, teachers need to create a new set of classroom languages and norms to make their own teaching practices more inclusive. In particular, it may be necessary for teachers in the current multicultural or globalised educational contexts where the diversity of student body is increasing, to have multiple sets of classroom languages and norms in an attempt to accommodate diverse student needs. In the CMIC course, for example, utilising different sets of criteria to facilitate and evaluate students' learning might be required in the different student cases 
Lee, K. (accepted). Implementing computer-mediated intercultural communication in English education: A critical reflection on its pedagogical challenges. Journal of Computer Assisted Learning.

discussed in the previous section.

Teachers' critical examination can open up, in turn, the possibility for involving students in critical reflection about their own developing subjectivities. It can be beneficial for students to be invited to reflect on the construction of their own subjectivities (i.e., identities) as part of the course interactions. Those subjectivities in such courses might include being an 'EFL learner', an 'English speaker', a 'career developer', a 'traveller' etc., and the open discussion of those issues implicates both their own personal motivation and the more collective issue of what it means to be a good or bad student (or English speaker). In this case, the diverse discourses that the students bring into classroom discussions can be organically fed into teacher's languages. Doing so may more effectively guide the adoption of the CMIC in language education in a more pedagogically, socially, and culturally sensitive way.

\section{Conclusion}

This article addresses an existing gap in current literature, which to a large extent focuses on the positive outcomes of implementing CMIC activities in language education, while neglecting concomitant pedagogical challenges and negative consequences. The qualitative and self-reflective nature of the author's narratives in this article can, it is hoped, offer readers some useful insights into some of the pedagogical challenges experienced by teachers and students in the CMIC-implemented classroom. The author employed several methodological strategies (e.g., member-checking and data-triangulation) - in order to increase the trustworthiness of her findings that were also clearly informed and supported by the selected theoretical framework. Nevertheless, it can be easily seen as just "a" single story among many possible ones about what happened in "a" single classroom. In fact, the author's own attempt to reanalyse the previously collected data, effectively demonstrates that taking up a different analytical perspective allows a researcher (or analyst in Tate, 2007) to focus on very different moments of the selected pedagogical event and/or interpret the same moments very differently. In that sense, the motivation for publishing this article is not to argue that the present story is the only legitimate translation of the events but rather to open up a more productive conversation-welcoming multiple voices either informed by different theoretical perspectives or coming from diverse cultural contexts.

The author also hopes reading this article can help teachers, especially those planning or conducting similar pedagogical initiatives in their own classrooms, to become more aware of the unequal learning and living conditions among EFL students and to be better prepared to address some of the pedagogical challenges that may arise from their attempts. The three teaching principles suggested in this article will not provide teachers with universal solutions to all of those issues. Rather, they invite teachers to 
Lee, K. (accepted). Implementing computer-mediated intercultural communication in English education: A critical reflection on its pedagogical challenges. Journal of Computer Assisted Learning.

transform their pedagogical beliefs fundamentally, to understand the purpose of their teaching differently, and to take more sensitive approaches to teaching their students. At first sight, teachers may find the idea of putting those principles into practice demanding. However, it needs to be emphasised that the suggested principles do not impose "add-on" teaching responsibilities on teachers, increasing their workload, but rather provide useful teaching ideas that are suitable for the open-ended and studentcentred nature of CMIC activities. Two critical conditions for the successful adoption of the principles can be briefly recapitulated here. First, the principles need to be carefully taken into consideration from the design stage; so that more creative and/or direct learning activities can be developed and put in place. Second, the principles need to be fully embedded in everyday interactions between teachers and students; students (not only teachers) should be invited as active participants in (or initiators of) the principleguided activities, such as creating "teachable/learnable" moments and new classroom norms.

It is clear that technological developments provide great pedagogical opportunities to improve EFL learning and teaching practices among other possibilities by allowing for more authentic English conversation (or intercultural communication) to take place among EFL students across the globe. The present author's experiences are consistent with the prevailing claims such that there is a wide range of technological tools available, including those specifically designed for the CMIC-implemented language classroom (i.e., CaMP-site). Indeed, utilizing those tools itself does not pose particular technical problems for teachers and students in such educational contexts. Going back to the starting point of this article, a lot of narratives in the current literature around CMIC-oriented language teaching are rather positive about the technological potential, while less critical or sensitive about the pedagogical challenges which have been the focus of this paper. Now, as both technologies and the educational applications of those technologies mature, it is timely for educational researchers to turn their focus from the technological implications of their research onto the more subtle but important social and cultural implications of their practice.

\section{References}

Aghaee, N., \& Keller, C. (2016). ICT-supported peer interaction among learners in Bachelor's and Master's thesis courses. Computers \& Education, 94, 276-297.

Alothman, M., Robertson, J., \& Michaelson, G. (2017). Computer usage and attitudes among Saudi Arabian undergraduate students. Computers \& Education, 110, 127-142.

Ambrose, M., Murray, L., Handoyo, N. E., Tunggal, D., \& Cooling, N. (2017). Learning global health: a pilot study of an online collaborative intercultural peer group activity involving medical students in Australia and Indonesia. BMC medical education, 17(1), 10.

Apple, M. (1998). The curriculum: Problems politics and possibilities. New York, NY: Routledge.

Aronowitz, S., \& Giroux, H. (1991). Textual Authority, culture, and the politics of literacy. In M. Apple \& L. K. 
Lee, K. (accepted). Implementing computer-mediated intercultural communication in English education: A critical reflection on its pedagogical challenges. Journal of Computer Assisted Learning.

Christian-Smith (Eds.), The politics of the textbook (pp. 213-241). New York, NY: Routledge.

Aronowitz, S., \& Giroux, H. A. (1993). Education still under siege. Westport, CT: Greenwood Publishing Group.

Asterhan, C. S., \& Bouton, E. (2017). Teenage peer-to-peer knowledge sharing through social network sites in secondary schools. Computers \& Education, 110, 16-34.

Bourdieu, P. (1986). The forms of capital. In J. G. Richardson (Ed.), Handbook of theory and research for the sociology of education (pp. 241-258). New York, NY: Greenwood.

Bourdieu, P. (1991). Language and symbolic power. Cambridge, MA: Harvard University Press.

Bray, E. (2010). Using videomail (Vmail) effectively in online intercultural exchanges. CALL-EJ Online, 11(2).

Briones, E., \& Lara, L. (2016). Teaching Ethics in the University through Multicultural Online Dialogue/Educación ética en la Universidad a través del diálogo multicultural online. Comunicar, 24(47), 99.

Brutt-Griffler, J. (2002). World English: A study of its development. Clevedon, UK: Multilingual Matters.

Bryson, M., \& De Castell, S. (1994). Telling tales out of school: Modernist, critical, and postmodern "true stories" about educational computing. Journal of Educational Computing Research, 1(3), 199-221.

Burbules, N. C., \& Berk, R. (1999). Critical thinking and critical pedagogy: Relations, differences, and limits. In T. Popkewitz \& L. Fendler (Eds.), Critical theories in education: Changing terrains of knowledge and politics (pp. 45-65). New York, NY: Routledge.

Butler, Y. G. (2011). The implementation of communicative and task-based language teaching in the Asia-Pacific region. Annual Review of Applied Linguistics, 31, 36-57.

Byram, M. (1997). Teaching and assessing intercultural communicative competence. Clevedon, UK: Multilingual Matters.

Byram, M. (2012). Language awareness and (critical) cultural awareness- relationships, comparisons and contrasts. Language Awareness, 21(1-2), 5-13.

Carr, N. (2016). Pre-service teachers teaching about and across cultures using digital environments: the case of eTutor. Educational Media International, 53(2), 103-117.

Cheng, Y., \& Jiang, H. (2015). Instant messenger-based online discourse platform and its impacts on students' academic performances: An exploratory study in art and design education. Computers \& Education, 88, 315326.

Cho, H. (2016). Under co-construction: An online community of practice for bilingual pre-service teachers. Computers \& Education, 92, 76-89.

Cohen, L., Manion, L., \& Morrison, K. (2011). Research methods in education (7 $7^{\text {th }}$ ed.). Abingdon, UK: Taylor \& Francis.

Comber, B. (1997). Managerial Discourses: tracking the local effects on teachers' and students' work in literacy lessons. Discourse: Studies in the cultural politics of education, 18(3), 389-407.

Coskun, A. (2011). Investigation of the application of communicative language teaching in the English language classroom: A case study on teachers' attitudes in Turkey. Journal of Linguistics and Language Teaching, 2(1).

Cummins, J. (2001). Negotiating identities: Education for empowerment in a diverse society (2nd ed.). Los Angeles, 
Lee, K. (accepted). Implementing computer-mediated intercultural communication in English education: A critical reflection on its pedagogical challenges. Journal of Computer Assisted Learning.

CA: California Association for Bilingual Education.

Cummins, J. (2004). Multiliteracies pedagogy and the role of identity texts. In K. Leithwood, P. McAdie, N. Bascia \& A. Rodrigues (Eds.). Teaching for deep understanding: Towards the Ontario curriculum that we need (pp. 68-74). Toronto, Canada: Ontario Institution for Studies in Education of the university of Toronto and the Elementary Federation of Teachers of Ontario.

Cummins, J., Brown, K., \& Sayers, D. (2007). Literacy, technology, and diversity: Teaching for success in changing times. Boston, MA: Allyn \& Bacon.

Dean, M. (2010). Governmentality: Power and rule in modern society (2nd ed.). London, UK: Sage.

Ellsworth, E. (1989). Why doesn't this feel empowering? Working through the repressive myths of critical pedagogy. Harvard educational review, 59(3), 297-325.

Foucault, M. (1995). Discipline and punish: The birth of the prison. (A. Sheridan, Trans.). New York, NY: Vintage. (Original work published 1975)

Freire, P. (1995). Pedagogy of the Oppressed. New York, NY: Continuum. (Original work published 1970)

Freire, P. (1998). Teachers as cultural workers. Boulder, CO: Westview Press.

Genlott, A. A., \& Grönlund, Å. (2016). Closing the gaps-Improving literacy and mathematics by ict-enhanced collaboration. Computers \& Education, 99, 68-80.

Giroux, H. A. (1981). Schooling and the myth of objectivity: Stalking the hidden curriculum, McGill Journal of Education, 17(1), 282-304.

Giroux, H. A. (1988). Teachers as intellectuals: Toward a critical pedagogy of learning. Westport, CT: Greenwood Publishing Group.

Golafshani, N. (2003). Understanding reliability and validity in qualitative research. The Qualitative Report, 8(1), 597-607.

Hu, G. W. (2005). 'CLT is best for China' - An untenable absolutist claim. ELT Journal, 59(1), 65-68.

Jeon, J. (2009). Key issues in applying the communicative approach in Korea: Follow up after 12 years of implementation. English Teaching, 64(1), 123-150.

Jin, S. (2015). Action research using Facebook to promote Korean EFL learners' intercultural competence. Language Learning \& Technology, 19(3), 38-51.

Kayumova, A. R., \& Sadykova, G. V. (2016). Online collaborative cross-cultural learning: Students' perspectives. Journal of Organizational Culture, Communication and Conflict, 20, 248.

Ke, I. C. (2016). Deficient non-native speakers or translanguagers?. Journal of Asian Pacific Communication, 26(2), 280-300.

Kennedy, A. (2006). Globalisation, global English: 'futures trading' in early childhood education. Early Years, 26(3), 295-306.

Kim, T. (2013). Recent trends in English learning motivation research. Seoul, South Korea: Hankook Munhwasa.

Kramsch, C. (2014). Teaching foreign languages in an era of globalization: Introduction. The Modern Language Journal, 98(1), 296-311.

Kurek, M., \& Müller-Hartmann, A. (2017). Task design for telecollaborative exchanges: In search of new criteria. 
Lee, K. (accepted). Implementing computer-mediated intercultural communication in English education: A critical reflection on its pedagogical challenges. Journal of Computer Assisted Learning.

System, 64, 7-20.

Lave, J., \& Wenger, E. (1991). Situated learning: Legitimate peripheral participation. UK: Cambridge university press.

Lázár, I. (2015). EFL learners' intercultural competence development in an international web collaboration project. The Language Learning Journal, 43(2), 208-221.

Li, D. (1998). "It's always more difficult than you plan and imagine": Teacher's perceived difficulties in introducing the communicative approaches in South Korea. TESOL Quarterly, 32(4), 677-703.

Lin, A. (1999). Doing-English-Lessons in the reproduction or transformation of social worlds? TESOL

Quarterly, 33(3), 393-412.

Lincoln, Y. S., \& Guba, E. G. (1985). Naturalistic inquiry. Beverly Hills, CA: Sage.

Lee, K., Ardeshiri, M., \& Cummins, J. (2016). A computer-assisted multiliteracies programme as an alternative approach to EFL instruction. Technology, Pedagogy and Education, 25(5), 595-612.

Lee, K., \& Brett, C. (2013). What are student inservice teachers talking about in their online Communities of Practice?: Investigating student inservice teachers' experiences in a double-layered CoP. Journal of technology and teacher education, 21(1), 89-118.

Lee, K., \& Brett, C. (2015). An online course design for inservice teacher professional development in a digital age: the effectiveness of the double-layered CoP model. In Handbook of Research on Teacher Education in the Digital Age (pp. 55-80). Hershey, PA: IGI Global.

Liaw, M. L., \& English, K. (2017). Identity and addressivity in the "Beyond These Walls" program. System, 64, 7486.

Loncar, M., Barrett, N. E., \& Liu, G. Z. (2014). Towards the refinement of forum and asynchronous online discussion in educational contexts worldwide: Trends and investigative approaches within a dominant research paradigm. Computers \& Education, 73, 93-110.

Machado, L., Klein, A. Z., Freitas, A., Schlemmer, E., \& Pedron, C. D. (2016). The use of virtual worlds for developing intercultural competences. International Journal of Information and Communication Technology Education, 12(3), 51-64.

McLaren, P. (2003). Life in Schools: An Introduction to Critical Pedagogy in the Foundations of Education Arlington (4th ed.). New York, NY: Allyin and Bacon.

New London Group (1996). A pedagogy of Multiliteracies: Designing social futures. Harvard Educational Review, 66(1), 60-92.

Nunan, D. (2003). The impact of English as a global language on educational policies and practices in the AsiaPacific region. TESOL Quarterly, 37(4), 589-613.

O’Dowd, R. (2007). Evaluating the outcomes of online intercultural exchange. ELT Journal, 61(2), 144-152.

Peiser, G. (2015). Overcoming barriers: engaging younger students in an online intercultural exchange. Intercultural Education, 26(5), 361-376.

Rudenko, N. S., \& Krylova, S. G. (2016). Pilot study of the influence of a communicator's speech characteristics on a recipient's willingness to maintain interaction in cross-cultural online communication. Psychology in 
Lee, K. (accepted). Implementing computer-mediated intercultural communication in English education: A critical reflection on its pedagogical challenges. Journal of Computer Assisted Learning.

Russia: State of the art, 9(2).

Sandoval, C. (2000). Semiotics and languages of emancipation. In Methodology of the oppressed. Minneapolis, MN: University of Minnesota Press.

Scardamalia, M., \& Bereiter, C.(1994). Computer support for knowledge-building communities. The Journal of the Learning Sciences, 3(1), 265-283.

Schenker, T. (2012). Intercultural competence and cultural learning through telecollaboration. CALICO Journal, 29(3), 449-470.

Strauss, A. L. , \& Corbin, J. (1990). Basics of qualitative research: Grounded theory procedures and techniques. London, UK: Sage.

Tang, Y., \& Hew, K. F. (2017). Using Twitter for education: Beneficial or simply a waste of time?. Computers \& Education, 106, 97-118.

Tanghe, S., \& Park, G. (2016). "Build[ing] something which alone we could not have done": International collaborative teaching and learning in language teacher education. System, 57, 1-13.

Tate, S. A. (2007). Foucault, Bakhtin, Ethnomethodology: Accounting for hybridity in talk-in-interaction. Forum: Qualitative social research, 8(2): Art. 10.

Turula, A. (2017). Teaching presence in telecollaboration. Keeping an open mind. System, 64, 21-33.

Villar-Onrubia, D., \& Rajpal, B. (2016). Online international learning: Internationalising the curriculum through virtual mobility at Coventry University. Perspectives: Policy and Practice in Higher Education, 20(2-3), 7582.

Vygotsky, L. S. (1978). Mind in Society. Cambridge, MA: Harvard University Press.

Wach, A. (2015). Advanced Learners' Intercultural Experience Through Computer-Enhanced Technology: A Study of Polish and Romanian Students. In New Media and Perennial Problems in Foreign Language Learning and Teaching (pp. 21-38). Springer International Publishing.

Ware, P., \& Kessler, G. (2016). Telecollaboration in the secondary language classroom: case study of adolescent interaction and pedagogical integration. Computer Assisted Language Learning, 29(3), 427-450.

Willis, P. (2003). Foot soldiers of modernity: The dialectics of cultural consumptions and the 21 st century school. Harvard Educational Review, 73(3), 390-415.

Wong, C. Y. (2012). A case study of college level second language teachers' perceptions and implementations of communicative language teaching. Professional Educator, 36(2).

Woolard, K. A., \& Schieffelin, B. B. (1994). Language ideology. Annual review of anthropology, 23(1), 55-82.

Yang, S. C., \& Chen, J. J. (2014). Fostering foreign language learning through technology-enhanced intercultural projects. Language Learning \& Technology, 18(1), 57-75.

Yin, R.K., (1984). Case study research: Design and methods. Beverly Hills, CA: Sage.

Yin, R. K. (2003). Case study research, design and methods (3rd ed., vol. 5). Thousand Oaks, CA: Sage. 